\title{
Crystal Engineering in Continuous Plug-Flow Crystallizers
}

\author{
Maximilian O. Besenhard, ${ }^{\dagger}, \# \oplus$ Peter Neugebauer, ${ }^{\ddagger, \#}$ Otto Scheibelhofer, ${ }^{\dagger}$ and Johannes G. Khinast ${ }^{*}, \dagger,+$ \\ ${ }^{\dagger}$ Research Center Pharmaceutical Engineering (RCPE), 8010 Graz, Austria \\ ${ }^{\ddagger}$ Graz University of Technology, Institute of Process and Particle Engineering, 8010 Graz, Austria
}

\section{Supporting Information}

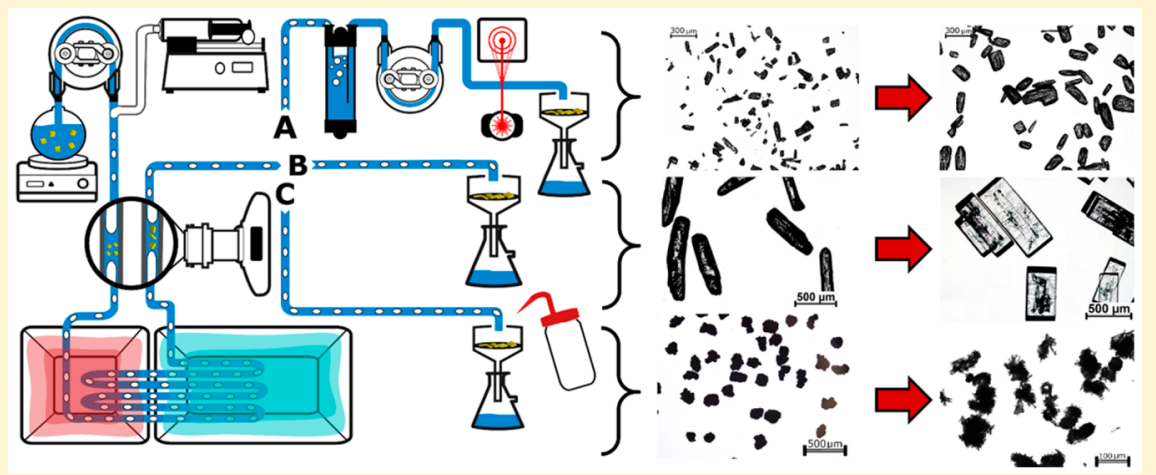

ABSTRACT: Size, shape, and polymorphic form are the critical attributes of crystalline particles and represent the major focus of today's crystallization process design. This work demonstrates how crystal properties can be tuned efficiently in solution via a tubular crystallizer that facilitates rapid temperature cycling. Controlled crystal growth, dissolution, and secondary nucleation allow a precise control of the crystal size and shape distribution, as well as polymorphic composition. Tubular crystallizers utilizing segmented flow such as the one presented in our work can provide plug flow characteristics, fast heating and cooling, allowing for rapid changes of the supersaturation. This makes them superior for crystal engineering over common crystallizers. Characterization of particle transport, however, revealed that careful selection of process parameters, such as tubing diameter, flow rates, solvents, etc., is crucial to achieve the full benefits of such reactors.

\section{INTRODUCTION}

Crystal engineering involves the ability to specifically tune the physicochemical properties of crystalline matter. As such, crystal engineering is based on an "understanding of intermolecular interactions in the context of crystal packing and the utilization of such understanding in the design of new solids with desired physical and chemical properties." ${ }^{1}$ This involves the arrangement of the atoms or molecules that comprise the crystal, as well as the size and morphology of individual crystals. While the lattice structure and associated defects determine a crystal's thermodynamic properties, the macromolecular properties such as shape determine the kinetic effects.

Pharmaceutical applications typically involve organic crystals of small molecules with a molecular weight $<500 \mathrm{~g} / \mathrm{mol}$ that can crystallize in several polymorphic forms, i.e., the same molecule(s) arranged in a different crystal lattice. Most new drugs on the market and in the development pipelines fall into class II biopharmaceuticals, and as such, exhibit a high permeability but low solubility. The low solubility poses significant challenges for drug release. ${ }^{2}$ While the solubility depends on the crystal structure (with amorphous forms usually providing the highest solubility), the dissolution rate is also affected by the total crystal surface area. The surface energy of a crystal is face-specific. ${ }^{3,4}$ Therefore, the crystal shape also affects the dissolution kinetics. ${ }^{5}$ This highlights the importance of the intra- and macromolecular properties of crystalline matter for a drug's bioavailability. Furthermore, crystal properties play a key role in pharmaceutical process development and production. Crystal size and shape determine the design of downstream operations, such as filtration, drying washing, mixing, tabletting, capsule filling, and powder flow properties in general. Different crystal facets expose the molecules at different orientations which can influence a wide range of properties such as catalytic activity, the tendency for electrostatic charging, wettability, hydrophobicity, and chemical stability. ${ }^{6-9}$ Therefore, crystal shape engineering can improve the long-term stability and extend the shelf life of crystalline pharmaceuticals. It should be pointed out that size and shape of crystalline matter are always distributions, which will affect the use of this particulate system dramatically.

Crystallization from solution is the prevailing process for separation and purification in pharmaceutical manufacturing. Tuning the crystals' physiochemical properties at this stage allows to define the product crystals' attributes at the beginning of the production.

Received: August 7, 2017

Revised: October 6, 2017

Published: October 10, 2017 
A common approach to crystal engineering in solution involves the use of additives. ${ }^{10-12}$ However, an addition of chemicals might require further separation steps and poses additional regulatory and quality control challenges for pharmaceutical production. An alternative approach is supersaturation control, which provides a nonchemical route to change crystal properties during the crystallization process, or directly after, while the crystals are still in solution. Tight supersaturation control is not trivial, and traditional batch crystallizers quickly reach their operational limits, if high supersaturation levels and rapid changes of the latter are required.

Tubular crystallizers (typically with an inner diameter of $<10$ $\mathrm{cm}$ and a length $>1 \mathrm{~m}$ ) are characterized by a high surface-tovolume ratio which facilitates faster heat transfer than in equivalent batch reactors. ${ }^{13-17}$

As the tube diameter gets smaller, the heat transfer rates increase. Tubular crystallizers are suitable for continuous operations and have successfully been applied to a wide range of applications for crystallization from solution. ${ }^{18-26}$

What these crystallizer designs have in common is that supersaturation is controlled via a predefined temperature trajectory along the flow direction. However, processing solid particles in small channels is challenging and becomes impossible as the tube diameter approaches the size of manufactured crystals. ${ }^{27}$ Depending on the process conditions, fouling or localized accumulations can result in clogging the reactor. Better particle dispersion and plug flow characteristics for the solid phase can be achieved via segmented flow, i.e., by feeding a gas or an immiscible liquid phase. ${ }^{18,28,29}$

The latter is less common in crystallization due the limited number of green nonpolar solvents of appropriate viscosity and miscibility. In addition, heating rates are reduced due to an additional heat capacity of the second fluid and the (generally) thicker wall film. Moreover, phase separation is required downstream.

In this work we demonstrate that a tubular crystallizer, operated in gas-liquid segmented flow mode, can carry out three important crystal-engineering processes continuously, and within minutes, by rapid changes of the supersaturation. First, particle transport in gas liquid segmented flows is discussed, followed by three sections on (i) the removal of fine crystals, (ii) the tuning of crystal shapes, and (iii) the transition between polymorphic forms. Other particle engineering challenges, including the engineering of the solvates/hydrate form or amorphous-crystalline transformations, can be addressed as well and will be the focus of future work.

\section{PARTICLE TRANSPORT IN GAS-LIQUID SEGMENTED FLOW}

As the tubing diameter decreases, surface tension forces become more relevant in multiphase flows, leading to various flow patterns depending on the gas- and liquid-flow rates as shown in Figure 1. At low gas flow rates, relative to the liquid phase, bubbles appear in the reactor; i.e., bubbly flow is observed. An increase in the gas flow rates leads to segmented flow (also referred to as gas-liquid Taylor flow or bubble train), which consists of elongated bubbles that can be many times longer than the channel diameter. At high gas-flow rates, annular flow is observed. If both liquid and gas flow rates are high, highly turbulent churn flow can occur. ${ }^{30}$ Besides the relative flow rates, the occurrence of a specific flow pattern depends on the fluid properties (e.g., viscosity $\mu$ and surface

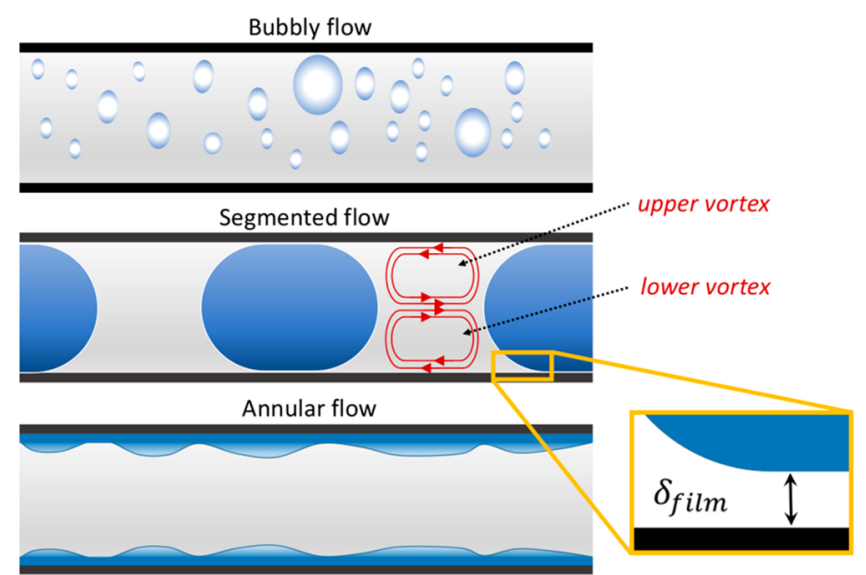

Figure 1. Gas liquid flow pattern in small channels. More details of the hydrodynamics can be found in the literature for slug flow ${ }^{96,97}$ and for annular flow. ${ }^{98}$

tension $\sigma$ ) affecting the liquid's behavior on the tube walls, ${ }^{31}$ and on the dimensions of the channel and junction. ${ }^{32-34}$

Since the 1960s, several groups have been able to successfully predict the flow patterns via flow maps using dimensionless parameters. ${ }^{35-40}$ However, most flow maps are applicable only close to the conditions for which they were obtained. ${ }^{41}$ For stable gas-liquid flow at flow rates $>1 \mathrm{~mL} / \mathrm{min}$ capillaries with an inner diameter of $<1 \mathrm{~cm}$ are required. Thus, tubing of $d_{\text {in }}=2$ $\mathrm{mm}$ was chosen for this study to process crystals between 1 and $500 \mu \mathrm{m}$ in segmented flow.

In gas-liquid segmented flows, heat and mass transfer, ${ }^{42,43}$ as well as particle transport in the slugs, is determined by a wetting film adjacent to the tubing wall (Figure 1, inset). This phenomenon has been extensively studied, and several expressions correlating film thickness to the channel diameter $d$ and the Capillary number $\mathrm{Ca}(=\mu \cdot \nu / \sigma)$ have been proposed. ${ }^{44-47}$ The film thickness increases with $\mathrm{Ca}$, i.e., with increasing flow rates/fluid velocities $\nu$. The effect of gravity on the film thickness is negligible, especially at small values of $\mathrm{Ca}<$ $10^{3},{ }^{48}$ but cannot be neglected for particle transport. The relative magnitudes of gravity, buoyancy, and drag forces determine if particles are suspended homogeneously within a slug or if they accumulate in the rear of the slug. ${ }^{43}$

To demonstrate how particle transport in a gas-liquid segmented flow is determined by the flow and particle properties, a D-mannitol suspension was pumped through a $d_{\text {in }}=2 \mathrm{~mm}$ tubing and monitored via a high-speed camera.

2.1. Materials and Methods: Particle Transport in Small Tubing. Three sieved fractions of D-mannitol (noncommercial sample of high $\alpha$-form content, spray-dried type, Roquette, France) were suspended in a saturated solution of $60 \%$ ethanol (ethanol: 99.8\%, denaturized, Carl Roth $\mathrm{GmbH}$, Germany) and $40 \%$ water (w/w) or saturated water. The size fractions were large $(150-180 \mu \mathrm{m})$, medium $(90-150 \mu \mathrm{m})$, and small $(50-80 \mu \mathrm{m})$. The solid mass fraction was $0.1 \mathrm{~g} / 100 \mathrm{~g}$ of solution. The suspension was pumped through a tubing of $10 \mathrm{~m}$ with a peristaltic pump at various flow rates, $\dot{V}_{\text {Susp. }}$. We used polysiloxane tubing (Versilic, Saint Gobain, France) with an inner diameter $d_{\text {in }}$ of $2.0 \mathrm{~mm}$ and an outer diameter $\left(d_{\text {out }}\right)$ of $4.0 \mathrm{~mm}$. The segmented flow was generated by injecting air via a syringe pump using a T-fitting. The ratio of suspension- to gas-flow rates was fixed to $\dot{V}_{\text {Susp }} / \dot{V}_{\text {Air }}=1.6$. After $1 \mathrm{~m}$ the tube was passing the field of view of a high-speed camera recording 


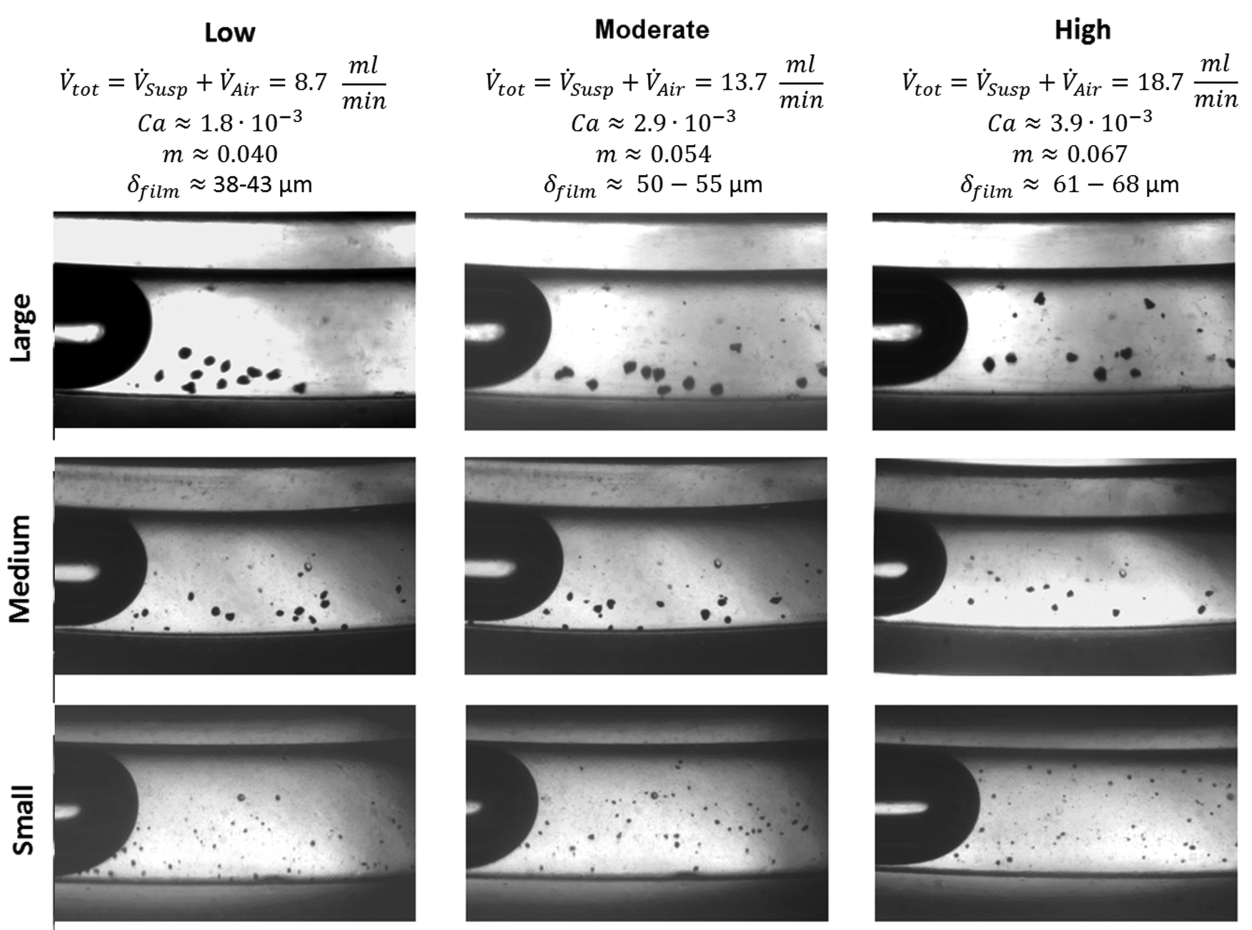

Figure 2. Particle dispersion in a gas (air) liquid (40\% water, 60\% ethanol) segmented flow. Direction of flow is from left to right. In each subimage air bubbles can be recognized entering from the left (dark black). For all flow rates (slow, moderate and fast), top row: large particles (150-180 $\mu \mathrm{m})$, middle row: medium particles $(90-150 \mu \mathrm{m})$, bottom row: small particles $(50-80 \mu \mathrm{m}) ; \dot{V}_{\text {Susp }} / \dot{V}_{\text {Air }}=1.6$.

at a frame rate of $500 \mathrm{fps}$, as described by us recently ${ }^{21}$ and as illustrated in Figure S1.

2.2. Results and Discussion: Particle Transport in Small Tubing. Images taken from the videos (all available for download in the Supporting Information) are shown in Figure 2. They highlight the influence of the flow rate and particle size on the dispersion of particles in the segments. Only at the highest flow rate $\left(\dot{V}_{\text {tot }}=18.7 \mathrm{~mL} / \mathrm{min}\right)$, the large D-mannitol crystals were dispersed throughout the slug, although not homogeneously. Low $\left(\dot{V}_{\text {tot }}=8.7 \mathrm{~mL} / \mathrm{min}\right)$ and moderate $\left(\dot{V}_{\text {tot }}\right.$ $=13.7 \mathrm{~mL} / \mathrm{min}$ ) flow rates caused accumulation of crystals in the lower part of the slug. Moreover, crystals accumulated at the rear end of the slug at the lowest flow rate. Also, mediumsized crystals spread more homogeneously at the highest flow rate, yet they were not perfectly dispersed throughout the segments. For low and intermediate flow rates, the particle concentration was higher in the lower vortex, but no accumulation in the rear end was observed even at the lowest flow rate. The smallest crystals were suspended almost homogeneously at the moderate flow rate. However, accumulation at the bottom was still observed at the lowest flow rate. In this context, accumulation should not be confused with sedimentation, i.e., crystals trapped in the wall film at the bottom of the slug that are not recirculated.

Yet, the results indicate that increasing the flow rates is an obvious choice for improving the dispersion of particles in the liquid segments separated by gas.

However, not only the flow rates impact the dispersion of particles, but also the wall film thickness increases with the increase in flow rates, as discussed above. The wall film thickness $\delta_{\text {film }}$ can be calculated using well-known semiempirical expressions, summarized in ref 30 . The range of wall thickness calculated via these expressions is shown for every case in Figure 2. A surface tension of $\sigma_{\mathrm{EtOH} 60 \%}=25.26 \times 10^{-3} \mathrm{~N} / \mathrm{m}$ was identified, based on the contact angle measurements. Surface tension data of all liquid phases in this study are presented in the Supporting Information, Table S1. Crystals can pass from one slug to another via the wall film (see Figure 1) if sedimented crystals are of similar or smaller size compared to the film thickness. As the film thickness increases at higher flow rates, larger crystals might travel between slugs, despite the improved dispersion. The images in Figure 2 (and the related videos) show that medium and especially small D-mannitol crystals can travel between neighboring slugs if they become trapped in the wall film at the bottom. The consequence is a broader residence time distribution (RSD) of particles. Hence, deviations from an ideal plug flow reactor were strongest for the small D-mannitol crystals, with a considerable number of crystals passing through the wall film. In contrast, the largest Dmannitol crystals remained in the original slug and did not pass through the liquid wall film for all studied flow rates. Thus, a very narrow RSD of the particulate phase in the tube is obtained, although the large particles were not dispersed homogeneously within each segment.

In summary, an increase in flow rate can improve particle dispersion within the segments but comes along with an increase in wall film thickness. This might allow larger particles to travel between slugs. In order to achieve ideal plug flow characteristics for the particulate phase, the film thickness should be significantly smaller than the particle diameter. This can be addressed for example by the solvent selection. Using pure water as a solvent significantly improves particle transport (minimizing/avoiding crystals passing through the liquid wall film) compared to ethanolic solutions. Because of its high surface tension $\sigma_{\mathrm{H}_{2} \mathrm{O}} \approx 70 \times 10^{-3} \mathrm{~N} / \mathrm{m}$, the liquid wall film thickness is reduced significantly, e.g., $\sim 50 \%$ compared to the $60 \%$ ethanolic solution used for this study. As a consequence, 
sedimentation of small crystals could be avoided using pure water as shown in Figure S2a.

Apart from an increase in the total flow rate, particle dispersion can also be improved by reducing the length of the liquid segments, e.g., by decreasing the ratio of $\dot{V}_{\text {Susp }} / \dot{V}_{\text {Air }}$ as shown in Figure S2b. In addition, an increase in the density of the liquid allows for a better dispersion as demonstrated in the Supporting Information providing additional videos of glass beads and sand dispersed in various solvents differing in density.

\section{FINES REMOVAL}

As reported by several groups, ${ }^{49-56}$ temperature cycling via single or multiple cycles is a simple, yet effective, procedure for tuning the crystal size distribution (CSD) and eliminating fines. Tubular crystallizers operated in segmented flow mode offer several advantages for temperature-cycling. They allow for sharp residence time distributions of the crystals in each stage of the reactor if operated properly (section 2), and facilitate particle dispersion at minimum agitation. This minimizes crystal collisions and hence possible aggregation or agglomeration events during the cooling stages, i.e., where the suspension is supersaturated. Agitation is also well-known to reduce the induction time for primary ${ }^{57}$ and secondary ${ }^{58}$ nucleation. Furthermore, there are no moving parts (e.g., stirrers) that could lead to attrition.

The concept of fines removal via subsequent heating and cooling cycles is as follows: a temporary increase in the temperature causes an overall decrease in the crystal size due to dissolution, with the smallest particles disappearing completely. The subsequent cooling stage(s) introduce(s) recrystallization, allowing the remaining crystals to grow back to their initial size and larger (assuming no new nuclei are formed). ${ }^{49,51}$ Consequently, the CSD is shifted toward larger crystals. If fines cannot be removed within a single temperature cycle, the maximum temperature can be increased. However, excessive dissolution needs to be avoided due to the high supersaturation levels during the successive cooling stage and the low surface area of remaining crystals. This makes the process slow and requires the temperature difference to be adjusted each time the size of the initial crystals change. Whether multiple temperature cycles are superior to a single temperature cycle to remove fines is determined by the size dependence of the crystal growth and dissolution rates. If the growth and dissolution rates are independent of the crystal size, the CSD does not change with more than one cycle. This is demonstrated in Figure 3 showing in silico results (of a population balance model) how multiple temperature cycles influence the CSD in the case of sizeindependent and size-dependent growth rate. Details of the population balance model are shown in the Supporting Information, section SI 3. Such population balance equation models have been used by several groups to understand the effect of cycling on the CSD and the crystal shape. ${ }^{59-62}$

Many systems show a clear size dependence of growth or dissolution rates, which is why most experimental and computational studies conclude that effective elimination of fines or efficient tuning of CSD cannot be achieved within a single cycle. Reasons for this size dependence are discussed, for example, in refs 63-66. Hence, multiple cycles allow for significant changes in the CSD. The same effect, i.e., a continuous change in the CSD with more cycles, is also expected for growth rate dispersion (different crystals of the same size exhibit different growth or dissolution rates) which is
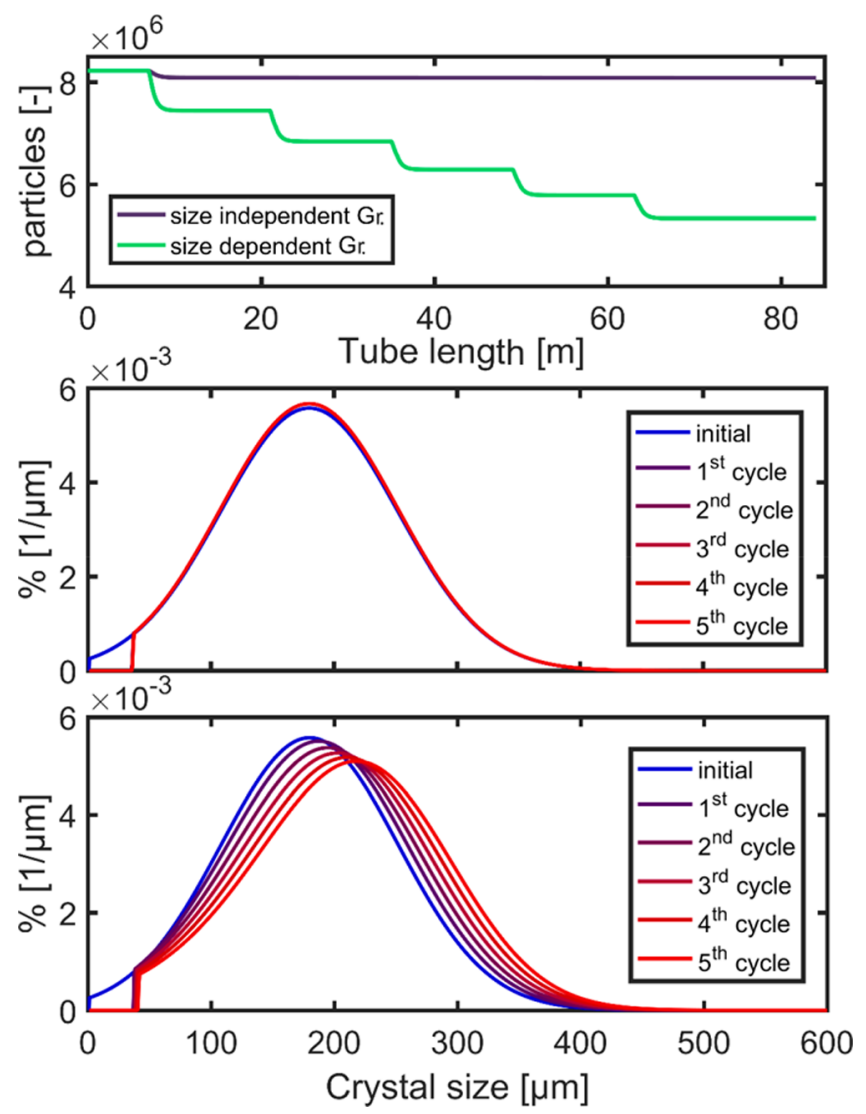

Figure 3. Changes in the number of particles (top) and PSD during temperature cycling determined via a population balance model assuming size-independent (middle) and size-dependent dissolution rates (bottom). The tube length $(0.875 \mathrm{~m}$ in the heating and cooling bath) did not allow equilibration $(S=1)$ after every heating and cooling step. The related supersaturation profile is shown in bottom of Figure S7.

sometimes mixed up with size-dependent growth or dissolution kinetics.

Here we demonstrate effective removal of fines from a commercial D-mannitol sample via the tubular crystallizer using multiple temperature cycles. Because of the fast heating and cooling rates high values of supersaturation could be achieved temporarily at a time scale way below the induction times, i.e., in the absence of primary or secondary nucleation events, allowing distinct changes in CSD within minutes.

3.1. Materials and Methods: Fines Removal from a Commercial D-Mannitol Sample. The D-mannitol powder used in our study (Pearlitol 160C, Roquette, France, used as received) has a broad CSD. The starting suspension was prepared by dispersing the D-mannitol powder $(0.3 \mathrm{~g}$ per 100 $\mathrm{g}$ ) in $500 \mathrm{~mL}$ of a saturated ethanolic (50\% ethanol $50 \%$ water) solution $(\mathrm{w} / \mathrm{w})$ in a $1000 \mathrm{~mL}$ round-bottom flask. Solubility data in the used solvent mixture were determined as described in the Supporting Information, section S5. The flask was briefly immersed in an ultrasonic bath to homogeneously disperse particles and separate aggregates formed during storage. The starting suspension was continuously stirred at $22.0{ }^{\circ} \mathrm{C}$ with a magnetic stirrer during the process. The stirrer bar and its speed of rotation were carefully selected to avoid the cone effect, i.e., sedimentation of larger particles in the bottom region, resulting in accumulation of larger particles in the flask when withdrawing from the suspension. The test measurements 


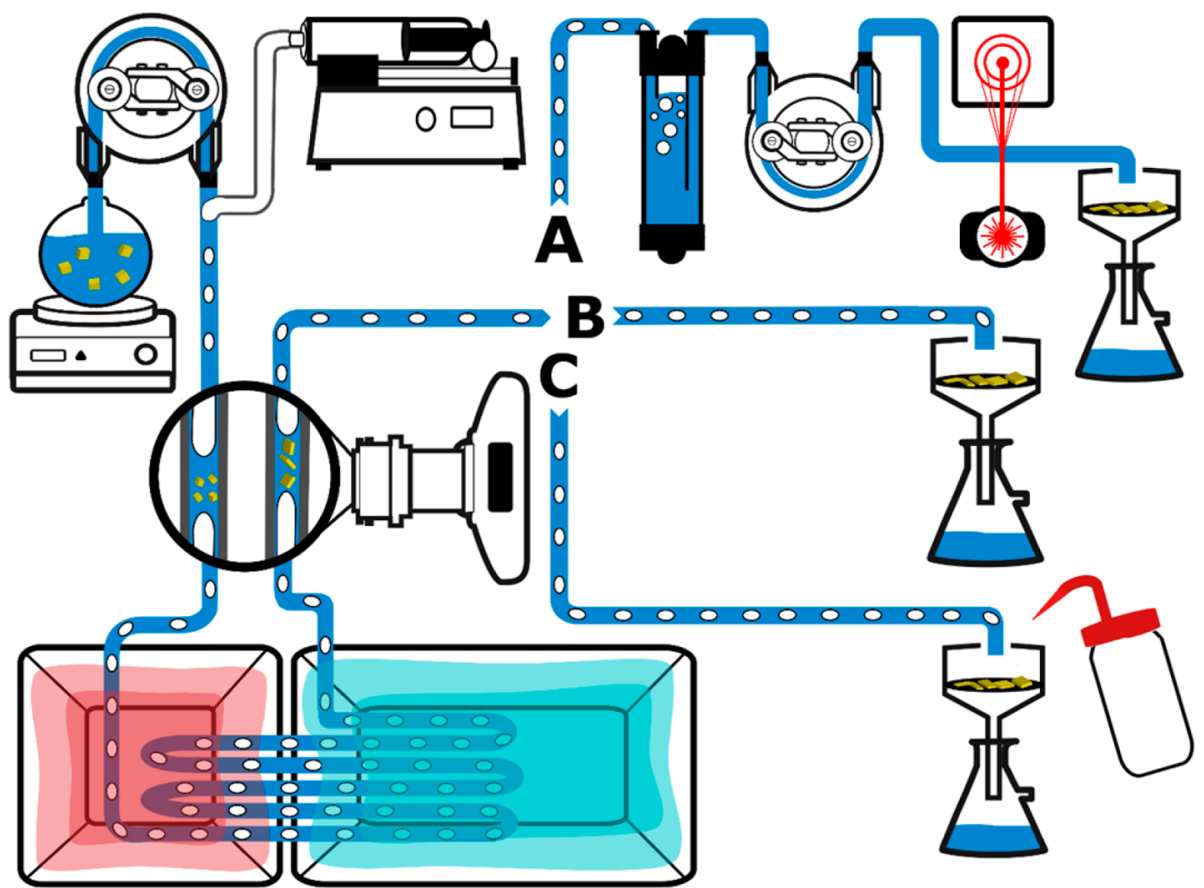

Figure 4. Schematic draft of setup used for fine removal (A), crystal shape (B), and polymorphism (C) studies. All three process start at the top left of the figure. A crystalline suspension is cycled through water baths via a peristaltic pump alternately passing two temperature-controlled water baths. Compartmentalization is achieved by introducing air bubbles via a syringe pump $(2 \times 100 \mathrm{~mL}$ syringes $)$ keeping the pressure almost constant for $\gg 30 \mathrm{~min}$. After passing the high-speed camera (monitoring crystals before and after temperature cycling simultaneously), the slurry was A: separated from the gas phase and pumped through the laser diffractometer before filtration; B: filtered; C: filtered while rinsing with Acetone.

(using the setup for laser diffraction measurements described below) showed that a uniform dispersion was achieved using a $4 \times 0.5 \mathrm{~cm}$ stirrer bar at $500 \mathrm{rpm}$, regardless of the fluid level in the flask. The CSD of the starting suspension changed only marginally, even after $2 \mathrm{~h}$ of stirring, as shown via FBRM (FBRM field unit, Mettler Toledo, Leicester, UK), see Figure S3.

To study the effect of various temperature profiles on the CSD, the temperature cycling setup was assembled as explained in Figure 4, path A. The tube was aligned horizontally, with a maximum curvature of $\sim 0.4 \mathrm{~cm}^{-1}$ at the turns and initially filled with a saturated but crystal free solution. Two thermostatic baths at different temperatures generated compartments with temperature differences of 2,4 , or $6{ }^{\circ} \mathrm{C}$, depending on the respective experiment. The tubular crystallizer (polysiloxane tubing, $d_{\text {in }} 2 \mathrm{~mm}$ ) comprised 15 loops of $186 \mathrm{~cm}$. In each loop, the suspension was heated at first with the tube immersed in a warm bath ( $\left.47 \mathrm{~cm} ; 24 / 26 / 28{ }^{\circ} \mathrm{C}\right)$, and subsequently cooled in the cooling water bath $\left(113 \mathrm{~cm}, 22^{\circ} \mathrm{C}=\right.$ room temperature $) .2$ $\times 13 \mathrm{~cm}$ of tubing per loop were used for crossovers from one bath to the other (room temperature = temperature of cooling bath). The unequal partitioning of the tube between the two water baths was used since the dissolution of crystals was expected to be faster than their growth. One meter of tubing was added before the inlet and after the outlet of the reactor. Thus, the total length of the tubular crystallizer was $30 \mathrm{~m}$.

Suspension and air flow rates were set to $\dot{V}_{\text {Susp }}=8.5 \mathrm{~mL} / \mathrm{min}$ and $\dot{V}_{\text {Air }}=5.2 \mathrm{~mL} / \mathrm{min}$, respectively (i.e., moderate flow rates according to section 2). For all settings, initial tests were performed to ensure the absence of primary nucleation by pumping clear saturated solutions through the tubular crystallizer passing the camera.
In order to quantify the changes in the fines content, the CSD was measured immediately. Instead of (error-prone) offline analysis, online laser diffraction was utilized (HELOS, Sympatec GmbH, Germany equipped with a LIXELL flow cell). The product suspension, i.e., the suspension exiting the tubing, was fed into a round $30 \mathrm{~mL}$ bottomed flask kept at 22 ${ }^{\circ} \mathrm{C}$ via a thermostatic bath to remove the gas phase before passing the suspension through a flow cell (measurement duration: $15 \mathrm{~s}$, measuring range of size: $4.5-800 \mu \mathrm{m})$, see Figure 4, path A.

To compare the multiple-cycles process to a single-cycle one, additional batch experiments were performed. For the batch experiments, the starting suspension was prepared as described above and heated at $0.1{ }^{\circ} \mathrm{C} / \mathrm{min}$, i.e., considerably slower than via the tubular crystallizer due to the smaller heat transfer rate in batch, to a temperature of $22.5{ }^{\circ} \mathrm{C}$ or $23{ }^{\circ} \mathrm{C}$ at which it was kept for $3 \mathrm{~min}$ before being cooled to the initial temperature of $22.0{ }^{\circ} \mathrm{C}$ at $0.1{ }^{\circ} \mathrm{C} / \mathrm{min}$. Higher temperatures were not possible due to complete dissolution. The suspension was analyzed immediately after the cycle via laser diffraction as described above.

3.2. Results and Discussion: Fines Removal from a Commercial D-Mannitol Sample. Figure 5 (top) shows the CSD of the starting suspension compared to products after temperature cycling in the tubular crystallizer at temperature differences of $2{ }^{\circ} \mathrm{C}, 4{ }^{\circ} \mathrm{C}$, and $6{ }^{\circ} \mathrm{C}$. Respective microscope pictures of the product crystals can be found in Figure 6 . Clearly, with an increasing temperature difference the number of fines decreases. Simultaneously, particles of more than 400 $\mu \mathrm{m}$ appear in the product.

Because of the fast cycling, $<45$ s per cycle, the suspension was not in equilibrium at the end of each cycle, i.e., $S \neq 1$ (supersaturation is defined as the ratio of concentration and 

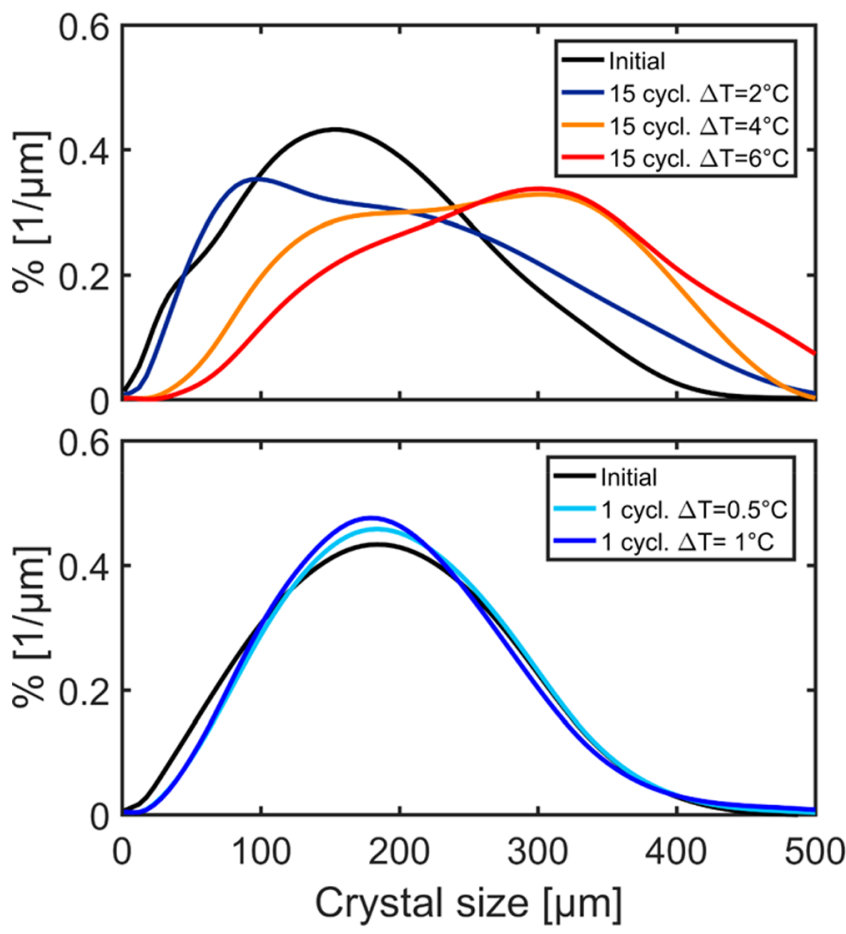

Figure 5. Measured crystal size distributions of the D-mannitol suspension cycled (top) multiple times via the tubular crystallizer and (bottom) once in batch.

solubility, $S=c(w / w) / c^{*}(w / w)$, throughout this work). The temperature profile was calculated using the model described in the Supporting Information (sections S3 and 6), yielding minimum and maximum temperatures of $T_{\min }=22.1^{\circ} \mathrm{C}$ and $T_{\max }=24.9^{\circ} \mathrm{C}$ (see Figure S13). This $T_{\max }$ corresponds to an undersaturation of $S_{\min }=0.87$. Rapid temperature cycling in the tubular reactor allowed for high average super- and undersaturations, $\frac{1}{t_{\text {end }}-t_{\text {start }}} \int_{t_{\text {start }}}^{t_{\text {end }}}|S(t)-1| \mathrm{d} t \gg 1$, enhancing dissolution and growth.

These high average super- and undersaturations facilitated a more significant change in the CSD via rapid temperature cycling in the tubular crystallizer than via a single temperature cycle performed in batch (see Figure 5, bottom) within shorter time. Tubular crystallizer: 15 cycles, $11 \mathrm{~min}$; batch: 1 cycle, 13 or $23 \mathrm{~min}$ ). However, fines removal considering the achieved minimal crystal size after cycling was only superior to batch, if the temperature differences exceeded $\Delta T=2{ }^{\circ} \mathrm{C}$.

\section{CRYSTAL SHAPE TUNING}

Controlling crystal shape is commonly achieved via the addition of growth inhibitors. The face-selective adsorption of these additives decelerates or even blocks growth of the specific facets to control the crystal shape. However, additives increase costs and may add to the complexity of the process. Additives are frequently toxic and require further downstream processes, such as recrystallization and separation. ${ }^{9}$ Furthermore, the solvent can influence the integration of solute molecules into the crystal surface, and hence, the crystal shape. This effect is particularly pronounced if the chemical structure of the solvent and the solute are related. The molecular conformation, solvation, and clustering of the solute is also affected by the solvent. ${ }^{67,68}$ However, the occurrence and stability of polymorphic forms do strongly depend on the solvent, which a)

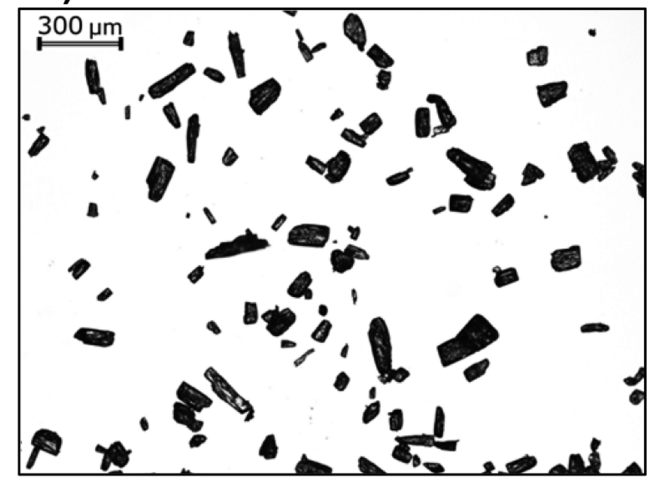

c)

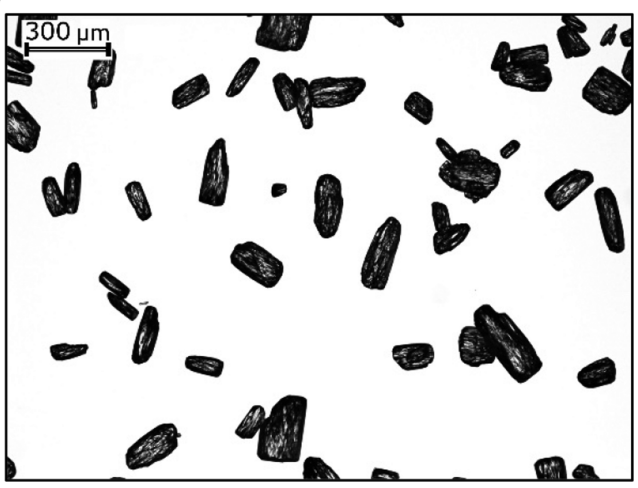

b)

d)
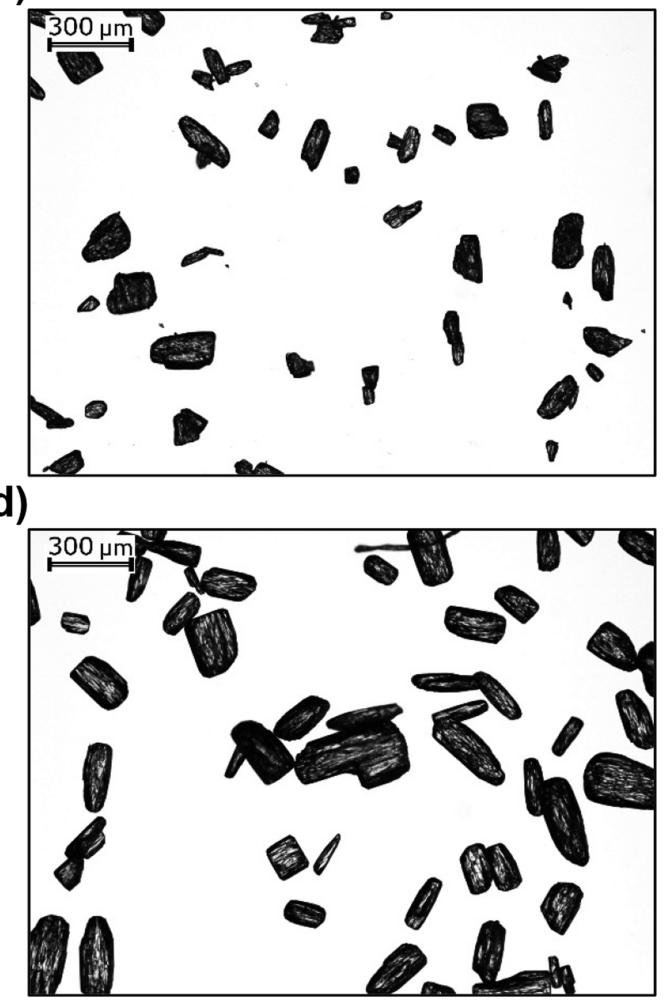

Figure 6. Microscope pictures of product crystals after passing through the tubular crystallizer for different temperature gradients. $(\mathrm{a}) \Delta T=0{ }^{\circ} \mathrm{C}$ (constant temperature in both baths, i.e., $22{ }^{\circ} \mathrm{C}$ ). (b) $\Delta T=2{ }^{\circ} \mathrm{C}$. (c) $\Delta T=4{ }^{\circ} \mathrm{C}$. (d) $\Delta T=6{ }^{\circ} \mathrm{C}$. 
Table 1. Settings and Initial Supersaturation Levels of Shape Tuning Experiments

\begin{tabular}{lccc} 
& cold bath $\left(17.0^{\circ} \mathrm{C}\right)$ & warm bath $\left(25.0^{\circ} \mathrm{C}\right)$ & start. susp. $\left(22.0^{\circ} \mathrm{C}\right)$ \\
solubility $c^{*}[\mathrm{~g} / 100 \mathrm{~g} \text { solv. }]^{21}$ & 18.40 & 25.50 & 22.6 \\
supersaturation $[-]$ & 1.23 & 0.89 & 1 \\
\hline
\end{tabular}

is one reason for the usually very limited number of suitable solvent candidates.

Yet, one more strategy for engineering the shape involves manipulation of the supersaturation, for example, by temperature cycling of the slurry. Employing adequate saturation control in batch processes is known as a simple and highly effective method to control crystal size., ${ }^{9,}$ Only recently, attempts have been made to influence not only the size, but also the shape of crystals via this approach. ${ }^{8,9,56,70,71}$ Still, most studies on crystal shape tuning are of theoretical nature. Limitations of analytical tools to quantify the multidimensional shape of microcrystals have been recognized as a major bottleneck in controlling the crystal shape. ${ }^{70,72}$ However, recent advances in 2D-image particle analysis allow the study of $3 \mathrm{D}$ crystal shapes. ${ }^{73-76}$ All these studies demonstrate that the morphology of a growing crystal evolves toward a steady-state. In contrast, dissolving crystals do not evolve toward such a steady-state. Hence, a crystals shape after multiple dissolution and recrystallization cycles is the combination of the stable steady-state growth morphology and the nonsteady dynamic dissolution morphology. This explains why a considerable change in crystal shape, i.e., a change in the relative surface area of the crystal facets sufficient to shift the physiochemical properties, many temperature cycles. Each of these, with significant dissolution during the heating stage. As such, crystal shape control via temperature cycling usually requires long process duration, which makes it frequently impractical. ${ }^{1}$

In the current study, we present how the crystal shape of acetylsalicylic acid (a model substance commonly used for shape control studies) can be changed within minutes using a tubular crystallizer. Its ability to go from a dissolution stage at low undersaturation to a growth stage and then reverse this process within seconds allows for significant dissolution in a minimum amount of time without dissolving entire crystals.

4.1. Materials and Methods: Shape Tuning of Acetylsalicylic Acid Crystals. The starting material for shape-tuning experiments was obtained from the commercial acetylsalicylic acid (ASA) powder (ASA 3020, G.L. Pharma, Lannach, Austria) by sieving a fraction of $200-250 \mu \mathrm{m}$ (size refers to mesh size). Crystals of this size were rather uniform in shape, i.e., rods with a maximum length between 500 and 800 $\mu \mathrm{m}$ (see Figure 6a). In all ASA shape-tuning experiments, a saturated 96\% ethanol solution (ethanol: 96\%, denaturized, Carl Roth $\mathrm{GmbH}$, Germany) was used. A solid mass fraction of $0.5 \mathrm{~g}$ of powder per $100 \mathrm{~g}$ of solution was chosen, not to have more than five crystals per segment. This was done to prevent accumulation at the rear ends of the segments which is likely to occur at such low flow rates (see section 2: moderate flow rates) and can promote aggregation. Since the crystals sizes were considerably larger than the wall film thickness, ideal plug flow characteristics were achieved for the cycled crystals (see section 2).

The tubular crystallizer was designed and operated using the flow rates and unequal partitioning of the tube length as described in section 3.1. In addition, experiments were performed with an equal partitioning, i.e., $80 \mathrm{~cm}$ of tubing in the warm and cold bath. A process schematic is shown in
Figure 4, path B. Experiments were performed using 5, 10, and 15 cycles. The technical limit of the number of cycles or tube length depends on the maximum pressure the pumps can provide and the pressure drop of the used tube. With the described setup, there were no technical difficulties even when using longer tubing of up to $40 \mathrm{~m}$ (data not shown).

The process settings and information about concentration and supersaturation along the temperature cycler are provided in Table 1. The supersaturation values refer to an immediate change in temperature, not considering changes in concentration due to dissolution or growth. The solubility data for ASA were obtained from our previous studies. ${ }^{21}$ Temperatures in the water baths were chosen based on high-speed camera videos, monitoring the inlet and outlet, see Figure $7 \mathrm{a}$. The images allowed an initial estimation of successful shape tuning and the absence of nucleation events. The absence of primary nucleation was also tested by cycling a crystal free solution
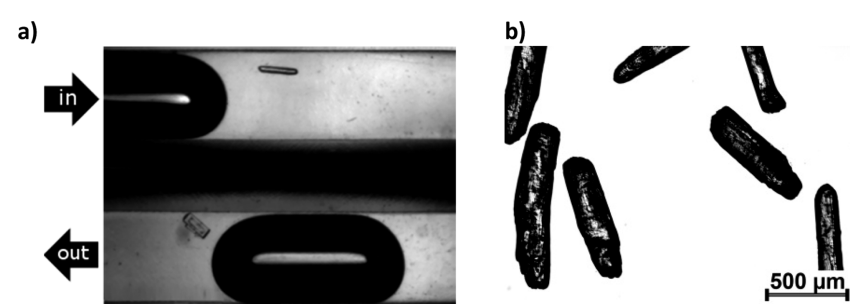

c)
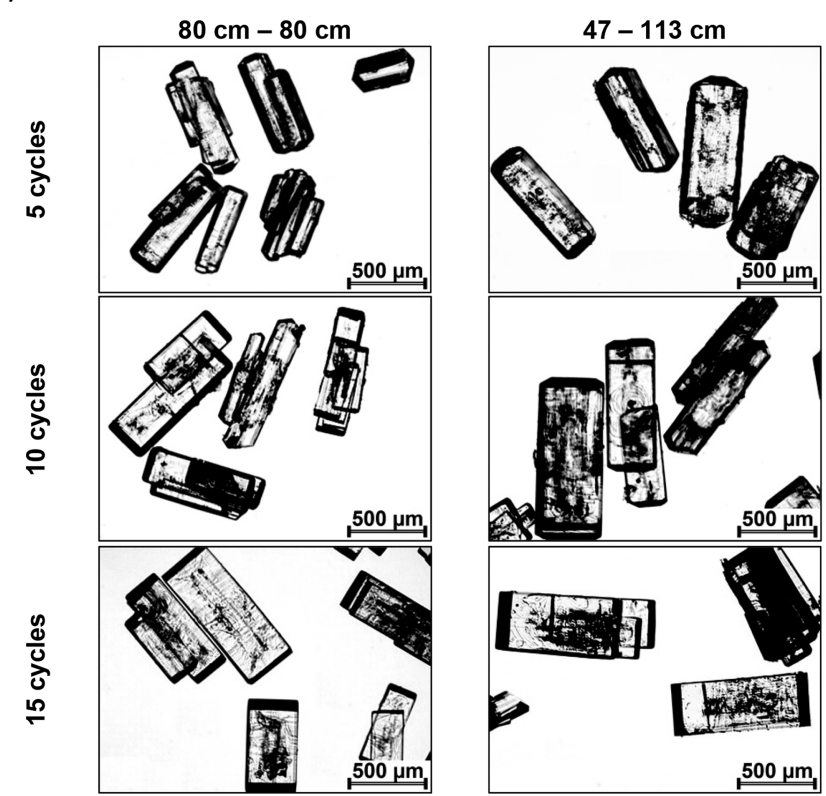

Figure 7. (a) High-speed camera image of a crystal entering the reactor (upper half, movement from left to right) and another crystal after shape tuning (lower half, movement from right to left. Microscope pictures of (b) feed and (c) product crystals after 5, 10, and 15 cycles, compared to a feed sample and a noncycled sample. Length specifications correspond to the tube length distributions per loop over the two water baths.). 
saturated at $22{ }^{\circ} \mathrm{C}$. Crystals were filtrated right after the outlet for further analysis.

4.2. Results and Discussion: Shape Tuning of Acetylsalicylic Acid Crystals. Figure $7 b, c$ shows micrographs comparing the rod-like ASA feed and the product crystals, i.e., those after temperature cycling in ethanol. A change in the shape was apparent already after five cycles $(3.5$ min residence time). The surface roughness decreased significantly, and the crystals lost their round shape and became rectangular and plate-like.

This effect was clearly enhanced after 10 cycles and became even more pronounced after 15 cycles showing a significant change in shape. Experiments with the unequal partitioning of the tubing ( $47 \mathrm{~cm}$ cold, $113 \mathrm{~cm}$ warm basin) showed a more efficient change of the crystal shape at the same number of temperature cycles.

In a typical batch processes, grinding effects by the stirrer can lead to a decrease in aspect ratio due to smoothening of elongated particles. ${ }^{77}$ In our experiments, product crystal shape was not affected by any moving parts. Plate-like crystals were obtained and no abrasion was observed, resulting in a narrow CSD and well-defined crystals. The described tubular crystallizer design, with each temperature cycle lasting $<1$ min, allows facile control of the crystal shape by increasing or reducing the number of cycles.

\section{POLYMORPHISM CONTROL}

Following Ostwald's rule of stages, the rate of nucleation of a metastable form is higher than that of the stable form. However, the polymorphic form with the fastest growth rate (which depends on the material, but is frequently the most stable polymorph) will eventually prevail regardless of the rate of primary or secondary nucleation. In addition, kinetic nucleation theory indicates that the primary nucleation rate of a metastable form is never the highest over the entire supersaturation range. ${ }^{78,79}$ Thus, the occurrence of a specific polymorph after crystallization is largely determined by its nucleation and growth kinetics in competition with other polymorphic forms. Conversion between polymorphs can occur during various processes and even during handling of the dry powder (e.g., milling). Polymorphic conversion may take anywhere between seconds and decades, making the control of the specific polymorph an important quality parameter of manufacturing.

The conversion of a metastable into the most stable form in solution is likely to follow via a solvent-mediated (polymorphic) transformation (SMT).$^{80,81}$ This is a reliable route for obtaining the most stable polymorph in the solvent used. Because of the difference in free energy, the solubility of polymorphic forms differs from each other. SMT starts with dissolution of the metastable form followed by nucleation or growth of the more stable form. Most studies on SMT of smallmolecule crystals report nucleation of the more stable form to be the rate-limiting step. ${ }^{82-84}$ Since secondary nucleation is frequently reported to dominate SMT, i.e., nucleation of a more stable polymorph on a less stable polymorph (often referred to as cross nucleation), the transition kinetics depend not only on the temperature and supersaturation but also on the number and CSD (i.e., the total crystal surface) of both phases.

Because of the supersaturation-dependence of the dissolution rates, growth rates, and nucleation rates (including secondary nucleation), temperature cycling can be utilized to control SMT. ${ }^{85-87}$ As such, the tubular crystallizer described in this work provides a powerful tool for speeding up a polymorphic transition under highly controlled process conditions. The continuous process benefits from a number of advantages discussed above.

In this study, we use the described tubular crystallizer to study SMT. D-Mannitol was chosen as model substance since the crystal structures of the polymorphs are known ${ }^{88}$ and their difference in free energy and solubility has extensively been reported. ${ }^{89,90}$ Because SMT proceeds via nucleation rather large temperature differences were chosen to promote nucleation events which was avoided for the fine removal and shape tuning studies.

5.1. Set-Up: Polymorphism Control of D-Mannitol. Among the three polymorphs of D-mannitol, the most stable under environmental conditions and water is the $\beta$ form, followed by the $\alpha$-form. The least stable is the $\delta$-form. The $\alpha$ form has little energetic difference from the $\beta$-form and similar physiochemical properties. ${ }^{91,92}$ The $\delta$-form was shown to be kinetically stable during milling and after 5 years of storage at $25{ }^{\circ} \mathrm{C}$ and dry conditions. In pharmaceutical products, the $\beta$ form prevails since it is thermodynamically stable at RT, although the $\delta$-form is increasingly used due to its superior compaction properties, e.g., for tableting ${ }^{93}$ and roller compaction. $^{94}$

The (absolute) difference in free energy between these three polymorphs diminishes at lower temperatures and in ethanolwater mixtures, i.e., difference in solubility decreases with higher ethanol fractions. Therefore, a $60 \%$ ethanol and $40 \%$ water solution $(\mathrm{w} / \mathrm{w})$ solution was used for all polymorphism control experiments, preserving the stability of the $\alpha$ polymorph (solid mass fractions, as described below) in the initial suspension for several hours, as shown in Figure S4. Solubility data for $\beta$-form in the used solvent mixture were determined as described in the Supporting Information, section S5.

The experimental procedure for the polymorphism studies of D-mannitol using a tubular crystallizer is shown in Figure 4, path C. Similar to the experiments shown in section 3 the solvent was saturated with D-mannitol ( $\beta$-form) at $22{ }^{\circ} \mathrm{C}$. Defined powder mixtures of two polymorphs ( $\alpha$-form: noncommercial, spray-dried type; $\beta$-form: Pearlitol 160C, both from Roquette, France) were added to the saturated solution (saturated with $\beta$-form of D-mannitol at $22{ }^{\circ} \mathrm{C}$ ) to a solid mass fraction of $0.8 \%(\mathrm{w} / \mathrm{w})$. Hence, the total amount of processed crystalline material was $>5 \mathrm{~g} / \mathrm{h}$, which is enough for microscopic studies. However, industrial applications would require higher solid mass production rates. In order to minimize any size effects, sieved fractions of D-mannitol (80$120 \mu \mathrm{m}$ ) were used in all polymorphism-control experiments. Rapid temperature cycling was performed by pumping the suspension through the tubing (same flow rates and length as used in the previous studies) immersed in water baths, cooled up to $10^{\circ} \mathrm{C}$ and heated up to $40^{\circ} \mathrm{C}$. Because of the flow rates and the tube lengths the temperature in the suspension did not reach the respective temperature of the water baths. Using the model described in the Supporting Information (section S3), the minimum and maximum temperatures were estimated as $T_{\text {min }}=11.6{ }^{\circ} \mathrm{C}$ and $T_{\text {max }}=30.9^{\circ} \mathrm{C}$ at the biggest temperature difference (see Figure S14), corresponding to super- and under saturations of $S_{\max }=1.90$ and $S_{\min }=0.71$.

Product samples were obtained by immediately filtering the product suspension while rinsing it with acetone in order to avoid that residual water induces additional polymorphic 
Table 2. Experimental Data Polymorphism Control

\begin{tabular}{|c|c|c|c|c|c|c|}
\hline & \multicolumn{2}{|c|}{$\begin{array}{l}\text { mass fractions in the start. susp. (as } \\
\text { prepared) }\end{array}$} & \multirow{2}{*}{$\frac{\text { temp. water bath } 1}{\left({ }^{\circ} \mathrm{C}\right)}$} & \multirow{2}{*}{$\frac{\text { temp. water bath } 2}{\left({ }^{\circ} \mathrm{C}\right)}$} & \multicolumn{2}{|c|}{$\begin{array}{l}\text { mass fraction in the prod. susp. from } \\
\text { Raman spectra and PLS model }\end{array}$} \\
\hline & $\alpha$-form (\%) & $\beta$-form (\%) & & & $\alpha$-form (\%) & $\beta$-form (\%) \\
\hline starting susp. $t=0 \mathrm{~min}$ & 80 & 20 & & & $82 \pm 4$ & $18 \pm 4$ \\
\hline starting susp. $t=60 \mathrm{~min}$ & & & & & $77 \pm 4$ & $23 \pm 4$ \\
\hline$\Delta T=30^{\circ} \mathrm{C}$ & 80 & 20 & 10 & 40 & $59 \pm 4$ & $41 \pm 4$ \\
\hline$\Delta T=20{ }^{\circ} \mathrm{C}$ & 80 & 20 & 15 & 35 & $66 \pm 4$ & $34 \pm 4$ \\
\hline$\Delta T=10{ }^{\circ} \mathrm{C}$ & 80 & 20 & 20 & 30 & $68 \pm 4$ & $32 \pm 4$ \\
\hline starting susp. $t=0 \mathrm{~min}$ & 50 & 50 & & & $53 \pm 4$ & $47 \pm 4$ \\
\hline starting susp. $t=60 \mathrm{~min}$ & & & & & $56 \pm 4$ & $44 \pm 4$ \\
\hline$\Delta T=30{ }^{\circ} \mathrm{C}$ & 50 & 50 & 10 & 40 & $34 \pm 4$ & $66 \pm 4$ \\
\hline$\Delta T=20^{\circ} \mathrm{C}$ & 50 & 50 & 15 & 35 & $39 \pm 4$ & $61 \pm 4$ \\
\hline$\Delta T=10^{\circ} \mathrm{C}$ & 50 & 50 & 20 & 30 & $49 \pm 4$ & $51 \pm 4$ \\
\hline
\end{tabular}

transitions after the filtration. The polymorphic composition of the samples was determined via Raman spectroscopy (PerkinElmer Raman Station 400, Waltham, USA) and multivariate data analysis, i.e., by applying a PLS model. Details of the procedure, including processing of spectral data, generation and analysis of calibration sample, as well as a thorough description of the PLS model and its evaluation, are presented in the Supporting Information (section S4).

5.2. Results and Discussion: Polymorphism Control of D-Mannitol. The mixtures of the $\alpha$ - and $\beta$-forms in the starting suspension and the composition of the product suspension after temperature cycling are listed in Table 2 . For both powder mixtures, the fraction of the $\beta$-form in the product suspension increased and the $\alpha$-form decreased. The higher the temperature difference of the water bath was, the more pronounced was this effect. The formation of the $\delta$-form was never observed. Higher supersaturation is associated with higher nucleation rates, which agrees with an increase in the fraction of the $\beta$-form, associated with an increase in the temperature difference.

Primary nucleation was marginal as evident from preliminary studies cycling crystal free solutions while monitoring the outlet with the high-speed camera and the micrographs of collected samples. As can be seen in Figure 8 and from quantification, the
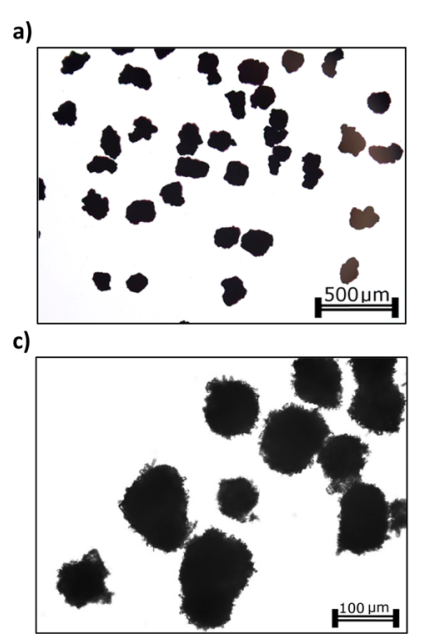

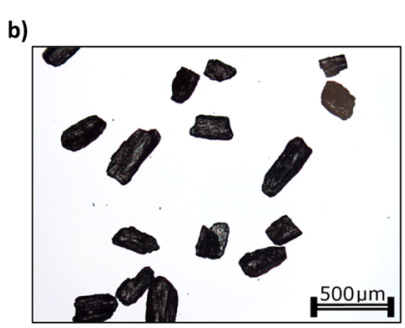

d)

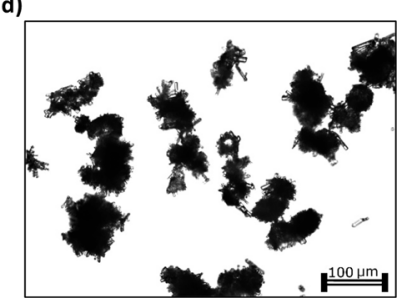

Figure 8. (a) Microscope picture of spray-dried $\alpha$-D-mannitol as received. (b) $\beta$-D-mannitol (Pearlitol 160C, Roquette, as received). Product crystals after temperature cycling (starting suspension: $80 \% \alpha$ form, $20 \% \beta$-form) (c) $\Delta T=20^{\circ} \mathrm{C}$, (d) $\Delta T=30^{\circ} \mathrm{C}$. product crystals clearly show secondary nucleation of the $\beta$ form on the surface of the $\alpha$-form crystals, indicating crossnucleation. A comparison of micrographs shows a subsequent growth resulting in sea-urchin-like particles for all initial compositions and all temperature differences, but no significant number of fines. Although, the quantity of the $\beta$-form in the second starting suspension $(50 \% \mathrm{w} / \mathrm{w})$ was higher than in the first one $(20 \% \mathrm{w} / \mathrm{w})$, a similar or even higher amount of the $\beta$ form was generated during cycling, especially for the highest temperature difference. This indicates that SMT is governed by cross nucleation rather than by the growth of the seeded $\beta$-form crystals. For D-mannitol, it has been reported that an $\alpha$ form seed crystal always induces the crystallization of the $\alpha$-form and the $\beta$-polymorph seed yields the $\beta$ - or $\alpha$-form, whereas the $\delta$ form seed yields the $\alpha$-form. ${ }^{95}$ However, the $\beta$-form can nucleate on the $\alpha$-form at high supersaturations, e.g., during quench-cooling. ${ }^{78}$ This agrees with our results showing cross nucleation of the $\beta$-form as was confirmed via Raman microscope studies on single particles as shown in Figure 9.

The tubular crystallizer can significantly accelerate SMT via temperature cycling as the difference in temperature increases, which is assigned to excessive secondary nucleation. Primary nucleation was prevented by keeping the time at supersaturation below the induction time. More cycles at high (or even higher) temperature differences seem to be the most convenient way to achieve a complete conversion to the $\beta$ form. This and the absence of moving parts with associated attrition facilitated the acceleration of SMT yielding big particles that can be filtered easily.

\section{SUMMARY AND CONCLUSIONS}

In this work a flexible tubular crystallizer operated in (gasliquid) segmented-flow mode was developed. Four different objectives of advanced particle-engineering were successfully demonstrated, i.e., dispersed particle transport, fines removal, shape tuning, and polymorphic composition. Despite the simple setup, crystal engineering could be performed via a continuous process with a considerable volume ( liters per hour) and residence times in the order of several minutes.

Precise control of the supersaturation is key for rational crystallization. By utilizing the heat transfer rates achievable in tubular crystallizer's precise supersaturation levels could be obtained. Moreover, high levels of super- and undersaturation, and the ability to switch between them within seconds allows for rapid dissolution and growth, while preventing primary nucleation, as well as secondary nucleation if needed. This 
a)

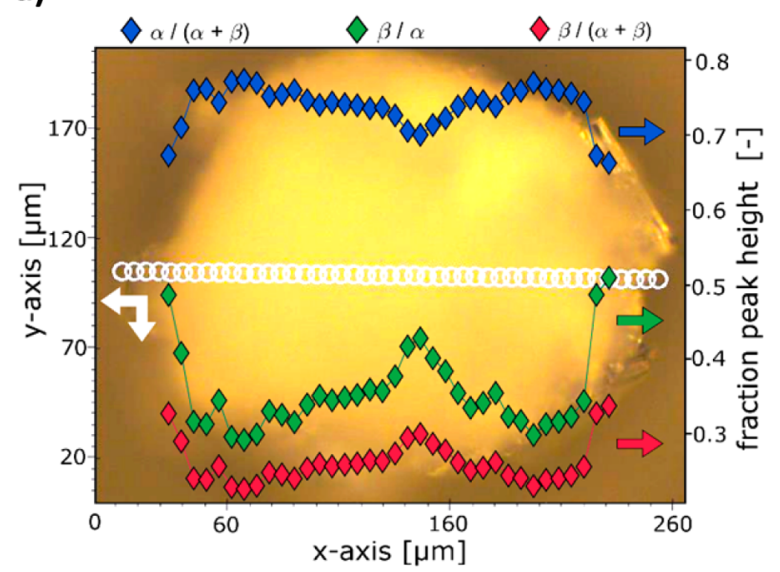

c)

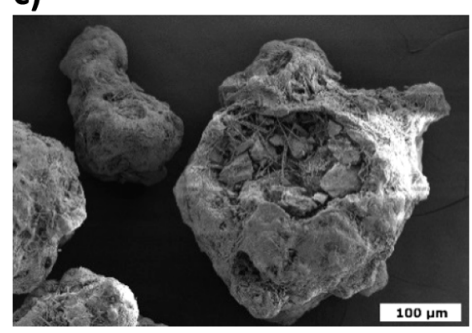

b)

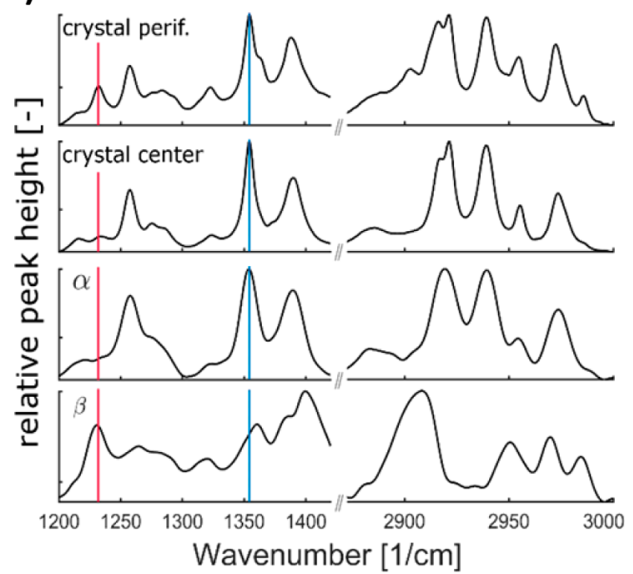

e)

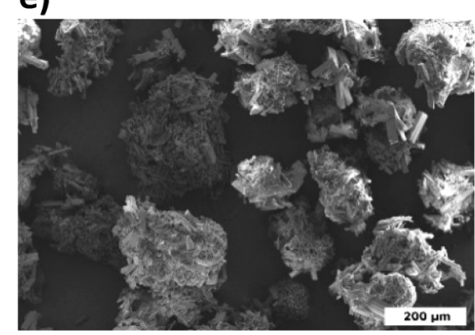

Figure 9. (a) Raman microscope studies on a single particle (initially mostly $\alpha$ form) after temperature cycling at $\Delta T=30^{\circ} \mathrm{C}$. The white circles on the microscope image show where Raman spectra were recorded. The relative heights of the peaks assigned to the $\alpha\left(1355 \mathrm{~cm}^{-1}\right)$ and $\beta\left(1233 \mathrm{~cm}^{-1}\right)$ form $^{89}$ are superimposed. (b) Raman spectra recorded at the periphery and at the center of the product particle compared to spectra of the seeded $\alpha$ and $\beta$ form. (c-e) SEM images of (c) seeded particles, (d) cycled at $\Delta T=20^{\circ} \mathrm{C}$, and (e) $\Delta T=30^{\circ} \mathrm{C}$. Details on the experimental procedure are provided in the Supporting Information, section S2.6.

occurs in the absence of any moving parts and at minimum agitation, while segmented flow allows for narrow residence time distributions.

However, achieving ideal plug flow characteristics for the particulate phase is not trivial as described above. Crystals can travel between slugs, if they become trapped in the wall film. Therefore, the wall film thickness should be smaller than the diameters of processed particulate matter. As shown in this section, the film thickness can be efficiently minimized by reducing the flow rates (which impairs particle dispersion in the segments), or using solvents with a higher surface tension (which is not always possible). Hence, the desired plug flow characteristics for liquid and solid phases in tubular reactors operated in segmented-flow mode can only be achieved at the right process settings in consideration of throughput and particle dispersion.

Fines removal via tubular crystallizers using segmented flow was studied via online laser diffraction, showing the potential of fast temperature cycling to shift the crystal size distribution significantly toward larger crystals within minutes. For the studied model system (D-mannitol, $\beta$-form) fines could be removed efficiently by increasing the temperature differences for cycling experiments. Other control options would be the number of cycles or the quantity of fed particles.

With respect to crystal shape tuning we showed how fast temperature cycling can be used to tune the shape of crystals. The studies using acetylsalicylic acid proved that facile control of the crystal shape is possible by manipulation of the number of cycles or the partitioning of heating and cooling segments. Other promising control options to tune crystal shapes in solution would be the temperature difference during cycling and changes in the solvent composition (not shown here).

The final section describes how fast changes in temperature, and hence switches between super- and undersaturation, affect solvent mediated phase transitions. For the tested transition, i.e., the transition from D-mannitol's $\alpha$-form to its $\beta$-form, cross nucleation of the $\beta$-form on the initially seeded $\alpha$-form showed to be the rate-limiting step. Transitions became more efficient with increasing differences in temperature during cycling. Hence, the temperature difference during cycling can be used to control the transition kinetics. Since primary nucleation should be avoided (depending on the desired product crystal size distribution) this difference in temperature cannot be increased arbitrarily. Nevertheless, the number of cycles used provide a convenient design tool to further control the final polymorphic composition.

In summary, tubular crystallizers can be used to tune the physiochemical properties of crystalline matter in a short amount of time without using any additives.

\section{ASSOCIATED CONTENT}

\section{S Supporting Information}

The Supporting Information (including the vidoes mentioned in the article) is available free of charge on the ACS Publications website at DOI: 10.1021/acs.cgd.7b01096.

Additional information about (1) used materials, (2) experimental procedures, and results, (3) the population balance and temperature models, and (4) the PLS model to quantify the $\alpha$ - and $\beta$-polymorph ratio via Raman spectroscopy (PDF)

Videos in AVI and MP3 format (ZIP) 


\section{AUTHOR INFORMATION}

\section{Corresponding Author}

*E-mail: khinast@tugraz.at. Tel.: +43 316873 30400. Fax: +43 3168731030400 .

\section{ORCID $\odot$}

Maximilian O. Besenhard: 0000-0002-5079-617X

\section{Author Contributions}

${ }^{\#}$ M.O.B. and P.N. contributed equally to this work.

\section{Notes}

The authors declare no competing financial interest.

\section{ACKNOWLEDGMENTS}

The authors would like to thank Sara Fathollahi, Reingard Sattler, and especially Michael Piller (all RCPE, Austria) for their support with the experimental setup and powder characterization. This work was funded by the Austrian Science fund (FWF-Projekt Nr. P 25374-N19).

\section{REFERENCES}

(1) Desiraju, G.; Vittal, J. J.; Ramanan, A. Crystal Engineering: A Textbook; World Scientific, 2011.

(2) Savjani, K. T.; Gajjar, A. K.; Savjani, J. K. Drug Solubility: Importance and Enhancement Techniques. ISRN Pharm. 2012, 2012, $1-10$.

(3) Heng, J. Y. Y.; Bismarck, A.; Williams, D. R. Anisotropic Surface Chemistry of Crystalline Pharmaceutical Solids. AAPS PharmSciTech 2006, 7, E12-E2.

(4) Muster, T. H.; Prestidge, C. A. Face Specific Surface Properties of Pharmaceutical Crystals. J. Pharm. Sci. 2002, 91, 1432-1444.

(5) Danesh, A.; Connell, S. D.; Davies, M. C.; Roberts, C. J.; Tendler, S. J. B.; Williams, P. M.; Wilkins, M. J. An In Situ Dissolution Study of Aspirin Crystal Planes (100) and (001) by Atomic Force Microscopy. Pharm. Res. 2001, 18, 299-303.

(6) Roeffaers, M. B. J.; Sels, B. F.; Uji-I, H.; De Schryver, F. C.; Jacobs, P. a; De Vos, D. E.; Hofkens, J. Spatially resolved observation of crystal-face-dependent catalysis by single turnover counting. Nature 2006, 439, 572-575.

(7) Yu, K.; Schmidt, J. R. Elucidating the Crystal Face- and Hydration-Dependent Catalytic Activity of Hydrotalcites in Biodiesel Production. J. Phys. Chem. C 2011, 115, 1887-1898.

(8) Lovette, M. A.; Browning, A. R.; Griffin, D. W.; Sizemore, J. P.; Snyder, R. C.; Doherty, M. F. Crystal Shape Engineering. Ind. Eng. Chem. Res. 2008, 47, 9812-9833.

(9) Snyder, R. C.; Studener, S.; Doherty, M. F. Manipulation of Crystal Shape by Circles of Growth and Dissolution. AIChE J. 2007, 53, 1510-1517.

(10) Green, D. C.; Ihli, J.; Thornton, P. D.; Holden, M. A.; Marzec, B.; Kim, Y.-Y.; Kulak, A. N.; Levenstein, M. A.; Tang, C.; Lynch, C.; Webb, S. E. D.; Tynan, C. J.; Meldrum, F. C. 3D visualization of additive occlusion and tunable full-spectrum fluorescence in calcite. Nat. Commun. 2016, 7, 13524.

(11) Anwar, J.; Boateng, P. K.; Tamaki, R.; Odedra, S. Mode of action and design rules for additives that modulate crystal nucleation. Angew. Chem., Int. Ed. 2009, 48, 1596-1600.

(12) Klapwijk, A. R.; Simone, E.; Nagy, Z. K.; Wilson, C. C. Tuning Crystal Morphology of Succinic Acid Using a Polymer Additive. Cryst. Growth Des. 2016, 16, 4349-4359.

(13) Eder, R. J. P.; Schmitt, E.; Grill, J.; Radl, S.; Gruber-Woelfler, H.; Khinast, J. G. Seed loading effects on the mean crystal size of acetylsalicylic acid in a continuous-flow crystallization device. Cryst. Res. Technol. 2011, 46, 227-237.

(14) Eder, R. J. P.; Schrank, S.; Besenhard, M. O.; Roblegg, E.; Gruber-Woelfler, H.; Khinast, J. G. Continuous Sonocrystallization of Acetylsalicylic Acid (ASA): Control of Crystal Size. Cryst. Growth Des. 2012, 12, 4733-4738.
(15) Besenhard, M. O.; Neugebauer, P.; Ho, C.-D.; Khinast, J. G. Crystal Size Control in a Continuous Tubular Crystallizer. Cryst. Growth Des. 2015, 15, 1683-1691.

(16) Pèrez-Calvo, J.-F.; Kadam, S. S.; Kramer, H. Determination of Kinetics in Batch Cooling Crystallization Processes - A Sequential Parameter Estimation Approach. AIChE J. 2016, 62, 3992-4012.

(17) Burns, M.; Natividad Marin, L.; Schneider, P. A. Investigations of a continuous Poiseuille flow struvite seed crystallizer - Mixer performance and aggregate disruption by sonication. Chem. Eng. J. 2016, 295, 552-562.

(18) Jiang, M.; Zhu, Z.; Jimenez, E.; Papageorgiou, C. D.; Waetzig, J.; Hardy, A.; Langston, M.; Braatz, R. D. Continuous-Flow Tubular Crystallization in Slugs Spontaneously Induced by Hydrodynamics. Cryst. Growth Des. 2014, 14, 851-860.

(19) Alvarez, A. J.; Myerson, A. S. Continuous Plug Flow Crystallization of Pharmaceutical Compounds. Cryst. Growth Des. 2010, 10, 2219-2228.

(20) Lawton, S.; Steele, G.; Shering, P.; Zhao, L.; Laird, I.; Ni, X. W. Continuous Crystallization of Pharmaceuticals Using a Continuous Oscillatory Baffled Crystallizer. Org. Process Res. Dev. 2009, 13, 13571363.

(21) Besenhard, M. O.; Hohl, R.; Hodzic, A.; Eder, R. J. P.; Khinast, J. G. Modeling a seeded continuous crystallizer for the production of active pharmaceutical ingredients. Cryst. Res. Technol. 2014, 49, 92108 .

(22) Méndez Del Río, J. R.; Rousseau, R. W. Batch and TubularBatch Crystallization of Paracetamol: Crystal size Distribution and Polymorph Formation. Cryst. Growth Des. 2006, 6, 1407-1414.

(23) Neugebauer, P.; Khinast, J. G. Continuous Crystallization of Proteins in a Tubular Plug-Flow Crystallizer. Cryst. Growth Des. 2015, $15,1089-1095$.

(24) Wiedmeyer, V.; Anker, F.; Bartsch, C.; Voigt, A.; John, V.; Sundmacher, K. Continuous Crystallization in a Helically Coiled Tube: Analysis of Flow Field, Residence Time Behavior and Crystal Growth. Ind. Eng. Chem. Res. 2017, 56, 3699-3712.

(25) McGlone, T.; Briggs, N. E. B.; Clark, C. A.; Brown, C. J.; Sefcik, J.; Florence, A. J. Oscillatory Flow Reactors (OFRs) for Continuous Manufacturing and Crystallization. Org. Process Res. Dev. 2015, 19, $1186-1202$

(26) Hohmann, L.; Gorny, R.; Klaas, O.; Ahlert, J.; Wohlgemuth, K.; Kockmann, N. Design of a Continuous Tubular Cooling Crystallizer for Process Development on Lab-Scale. Chem. Eng. Technol. 2016, 39, $1268-1280$.

(27) Roberge, D. M.; Ducry, L.; Bieler, N.; Cretton, P.; Zimmermann, B. Microreactor Technology: A Revolution for the Fine Chemical and Pharmaceutical Industries? Chem. Eng. Technol. 2005, 28, 318-323.

(28) Rasche, M. L.; Jiang, M.; Braatz, R. D. Mathematical modeling and optimal design of multi-stage slug-flow crystallization. Comput. Chem. Eng. 2016, 95, 240-248.

(29) Rossi, D.; Jamshidi, R.; Saffari, N.; Kuhn, S.; Gavriilidis, A.; Mazzei, L. Continuous-Flow Sonocrystallization in Droplet-Based Microfluidics. Cryst. Growth Des. 2015, 15, 5519-5529.

(30) Angeli, P.; Gavriilidis, A. Hydrodynamics of Taylor flow in small channels: a review. Proc. Inst. Mech. Eng., Part C 2008, 222, 737-751.

(31) Kawaji, M.; Mori, K.; Bolintineanu, D. The Effects of Inlet Geometry and Gas-Liquid Mixing on Two-Phase Flow in Microchannels. J. Fluids Eng. 2009, 131, 041302.

(32) Rajesh, V. M.; Buwa, V. V. Experimental characterization of gasliquid-liquid flows in T-junction microchannels. Chem. Eng. J. 2012, 207-208, 832-844.

(33) Yagodnitsyna, A. A.; Kovalev, A. V.; Bilsky, A. V. Flow patterns of immiscible liquid-liquid flow in a rectangular microchannel with $\mathrm{T}$ junction. Chem. Eng. J. 2016, 303, 547-554.

(34) Kacker, R.; Regensburg, S. I.; Kramer, H. J. M. Residence time distribution of dispersed liquid and solid phase in a continuous oscillatory flow baffled crystallizer. Chem. Eng. J. 2017, 317, 413-423. 
(35) Mandhane, J. M.; Gregory, G. A.; Aziz, K. A flow pattern map for gas-liquid flow in horizontal pipes. Int. J. Multiphase Flow 1974, 1, 537-553.

(36) Jayawardena, S. S.; Balakotaiah, V.; Witte, L. C. Flow Pattern Transition Maps for Microgravity Two-Phase Flows. AIChE J. 1997, 43, 1637-1640.

(37) Suo, M.; Griffith, P. Two-Phase Flow in Capillary Tubes. J. Basic Eng. 1964, 86, 576-582.

(38) Hewitt, G. F.; Roberts, D. N. Studies of Two-Phase Flow Patterns by Simultaneous X-Ray and Flash Photography; United Kingdom Atomic Energy Authority, 1969.

(39) Rezkallah, K. S. Weber number based flow-pattern maps for liquid-gas flows at microgravity. Int. J. Multiphase Flow 1996, 22, $1265-1270$

(40) El-Sebakhy, E. A. Flow regimes identification and liquid-holdup prediction in horizontal multiphase flow based on neuro-fuzzy inference systems. Math. Comput. Simul. 2010, 80, 1854-1866.

(41) Günther, A.; Kreutzer, M. T. Micro Process Engineering, Vol. 1: Fundamentals, Operations and Catalysis; Hessel, V.; Renken, A.; Schouten, J. C.; Yoshida, J.-I., Eds.; WILEY-VCH Verlag GmbH \& Co.: Weinheim, 2009.

(42) Asadi, M.; Xie, G.; Sunden, B. A review of heat transfer and pressure drop characteristics of single and two-phase microchannels. Int. J. Heat Mass Transfer 2014, 79, 34-53.

(43) Tan, J.; Lu, Y. C.; Xu, J. H.; Luo, G. S. Mass transfer performance of gas-liquid segmented flow in microchannels. Chem. Eng. J. 2012, 181-182, 229-235.

(44) Kreutzer, M. T.; Kapteijn, F.; Moulijn, J. A.; Kleijn, C. R.; Heiszwolf, J. J. Inertial and interfacial effects on pressure drop of Taylor flow in capillaries. AIChE J. 2005, 51, 2428-2440.

(45) Irandoust, S.; Andersson, B. Liquid film in Taylor Flow through a Capillary. Ind. Eng. Chem. Res. 1989, 28, 1684-1688.

(46) Fairbrother, F.; Stubbs, A. E. 119. Studies in Electroendosmosis. Part VI. The "Bubble-tube" Method of Measurement. J. Chem. Soc. 1935, 0, 527-529.

(47) Bretherton, F. P. The motion of long bubbles in tubes. J. Fluid Mech. 1961, 10, 166-188.

(48) Leung, S. S. Y.; Gupta, R.; Fletcher, D. F.; Haynes, B. S. Gravitational effect on Taylor flow in horizontal microchannels. Chem. Eng. Sci. 2012, 69, 553-564.

(49) Majumder, A.; Nagy, Z. K. Fines Removal in a Continuous Plug Flow Crystallizer by Optimal Spatial Temperature Profiles with Controlled Dissolution. AIChE J. 2013, 59, 4582-4594.

(50) Loï Mi Lung-Somarriba, B.; Moscosa-Santillan, M.; Porte, C.; Delacroix, a. Effect of seeded surface area on crystal size distribution in glycine batch cooling crystallization: a seeding methodology. J. Cryst. Growth 2004, 270, 624-632.

(51) Kim, S.; Wei, C.; Kiang, S. Crystallization Process Development of an Active Pharmaceutical Ingredient and Particle Engineering via the Use of Ultrasonics and Temperature Cycling. Org. Process Res. Dev. 2003, 7, 997-1001.

(52) Saleemi, A.; Rielly, C. D.; Nagy, Z. K. Automated direct nucleation control for in situ dynamic fines removal in batch cooling crystallization. CrystEngComm 2012, 14, 2196-2203.

(53) Abu Bakar, M. R.; Nagy, Z. K.; Rielly, C. D. Seeded Batch Cooling Crystallization with Temperature Cycling for the Control of Size Uniformity and Polymorphic Purity of Sulfathiazole Crystals. Org. Process Res. Dev. 2009, 13, 1343-1356.

(54) Nagy, Z. K.; Aamir, E.; Rielly, C. D. Internal Fines Removal Using Population Balance Model Based Control of Crystal Size Distribution under Dissolution, Growth and Nucleation Mechanisms. Cryst. Growth Des. 2011, 11, 2205-2219.

(55) Kacker, R.; Radoiu, M.; Kramer, H. J. M. Novel design integrating a microwave applicator into a crystallizer for rapid temperature cycling. A direct nucleation control study. Cryst. Growth Des. 2017, 17, 3766.

(56) Wu, Z.; Yang, S.; Wu, W. Application of temperature cycling for crystal quality control during crystallization. CrystEngComm 2016, 18, $2222-2238$.
(57) Liu, J.; Rasmuson, Å. C. Influence of Agitation and Fluid Shear on Primary Nucleation in Solution. Cryst. Growth Des. 2013, 13, 4385-4394.

(58) Lakerveld, R.; Van Krochten, J. J. H.; Kramer, H. J. M. An air-lift crystallizer can suppress secondary nucleation at a higher supersaturation compared to a stirred crystallizer. Cryst. Growth Des. 2014, $14,3264-3275$

(59) Lindenberg, C.; Krättli, M.; Cornel, J.; Mazzotti, M.; Brozio, J. Design and Optimization of a Combined Cooling/Antisolvent Crystallization Process. Cryst. Growth Des. 2009, 9, 1124-1136.

(60) Sarkar, D.; Rohani, S.; Jutan, A. Multiobjective Optimization of Semibatch Reactive Crystallization Processes. AIChE J. 2007, 53, 1164-1177.

(61) Sarkar, D.; Rohani, S.; Jutan, A. Multi-objective optimization of seeded batch crystallization processes. Chem. Eng. Sci. 2006, 61, 52825295.

(62) Noor, S.; Qamar, S. The space time CE/SE method for solving one-dimensional batch crystallization model with fines dissolution. Chin. J. Chem. Eng. 2015, 23, 337-341.

(63) Pantaraks, P.; Flood, A. E. Effect of Growth Rate History on Current Crystal Growth: A Second Look at Surface Effects on Crystal Growth Rates. Cryst. Growth Des. 2005, 5, 365-371.

(64) Mydlarz, J.; Jones, A. G. On the estimation of size-dependent crystal growth rate functions in MSMPR crystallizers. Chem. Eng. J. Biochem. Eng. J. 1993, 53, 125-135.

(65) Iggland, M.; Mazzotti, M. Population Balance Modeling with Size-Dependent Solubility: Ostwald Ripening. Cryst. Growth Des. 2012, $12,1489-1500$.

(66) Handbook of Industrial Crystallization; Myerson, A. S., Ed.; Butterworth-Heinemann, 2002.

(67) Meenan, P. A.; Anderson, S. R.; Klug, D. L. The Influence of Impurities and solvents on crystallization; In Handbook of Industrial Crystallization; Elsevier B.V., 2002.

(68) Watanabe, A.; Yamaoka, Y.; Takada, K. Crystal Habits and Dissolution Behavior of Aspirin. Chem. Pharm. Bull. 1982, 30, 29582963.

(69) Jiang, M.; Zhu, X.; Molaro, M. C.; Rasche, M. L.; Zhang, H.; Chadwick, K.; Raimondo, D. M.; Kim, K. K. K.; Zhou, L.; Zhu, Z.; Wong, M. H.; O'Grady, D.; Hebrault, D.; Tedesco, J.; Braatz, R. D. Modification of Crystal Shape through Deep Temperature Cycling. Ind. Eng. Chem. Res. 2014, 53, 5325-5336.

(70) Bajcinca, N.; de Oliveira, V.; Borchert, C.; Raisch, J.; Sundmacher, K. Optimal control solutions for crystal shape manipulation. Comput.-Aided Chem. Eng. 2010, 28, 751-756.

(71) Li, W.; Zhao, C.; Zou, B.; Zhang, X.; Yu, J.; Zhang, X.; Jie, J. Highly branched organic microcrystals via self-organization and growth kinetics manipulation. CrystEngComm 2012, 14, 8124.

(72) Patience, D. B.; Rawlings, J. B. Particle-shape Monitoring and Control in Crystallization Processes. AIChE J. 2001, 47, 2125-2030.

(73) Wang, X. Z.; Roberts, K. J.; Ma, C. Crystal growth measurement using $2 \mathrm{D}$ and $3 \mathrm{D}$ imaging and the perspectives for shape control. Chem. Eng. Sci. 2008, 63, 1173-1184.

(74) Simon, L. L.; Abbou Oucherif, K.; Nagy, Z. K.; Hungerbuhler, $\mathrm{K}$. Bulk video imaging based multivariate image analysis, process control chart and acoustic signal assisted nucleation detection. Chem. Eng. Sci. 2010, 65, 4983-4995.

(75) Borchert, C.; Sundmacher, K. Morphology evolution of crystal populations: Modeling and observation analysis. Chem. Eng. Sci. 2012, 70, 87-98.

(76) Borchert, C.; Temmel, E.; Eisenschmidt, H.; Lorenz, H.; SeidelMorgenstern, A.; Sundmacher, K. Image-Based in Situ Identification of Face Specific Crystal Growth Rates from Crystal Populations. Cryst. Growth Des. 2014, 14, 952-971.

(77) Kempkes, M.; Vetter, T.; Mazzotti, M. Monitoring the particle size and shape in the crystallization of paracetamol from water. Chem. Eng. Res. Des. 2010, 88, 447-454.

(78) Lee, E. H. A practical guide to pharmaceutical polymorph screening \& selection. Asian J. Pharm. Sci. 2014, 9, 163-175. 
(79) Davey, R. J.; Back, K. R.; Sullivan, R. a. Crystal nucleation from solutions - transition states, rate determining steps and complexity. Faraday Discuss. 2015, 179, 9-26.

(80) Ostwald, W. Studien über die Bildung und Umwandlung fester Körper. Z. Phys. Chem. 1897, 22, 289-330.

(81) Threlfall, T. Structural and Thermodynamic Explanations of Ostwald's Rule. Org. Process Res. Dev. 2003, 7, 1017-1027.

(82) Qu, H.; Louhi-Kultanen, M.; Rantanen, J.; Kallas, J. SolventMediated Phase Transformation Kinetics of an Anhydrate/Hydrate System. Cryst. Growth Des. 2006, 6, 2053-2060.

(83) O’Sullivan, B.; Barrett, P.; Hsiao, G.; Carr, A.; Glennon, B. In Situ Monitoring of Polymorphic Transitions. Org. Process Res. Dev. 2003, 7, 977-982.

(84) Nguyen, D. L. T.; Kim, K. J. Solvent-Mediated Polymorphic Transformation of $\alpha$-Taltirelin by Seeded Crystallization. Chem. Eng. Technol. 2016, 39, 1281-1288.

(85) Chow, K.; Tong, H. H. Y.; Lum, S.; Chow, A. H. L. Engineering of Pharmaceutical Materials: An Industrial Perspective. J. Pharm. Sci. 2008, 97, 2855-2877.

(86) O'Sullivan, B.; Glennon, B. Application of in Situ FBRM and ATR-FTIR to the Monitoring of the Polymorphic Transformation of D-Mannitol. Org. Process Res. Dev. 2005, 9, 884-889.

(87) Davey, R. J.; Guy, P. D.; Ruddick, A. J. The IV $\rightarrow$ III Polymorphic Phase Transition in Aqueous Slurries of Ammonium Nitrate. J. Colloid Interface Sci. 1985, 108, 189-192.

(88) Botez, C. E.; Stephens, P. W.; Nunes, C.; Suryanarayanan, R. Crystal structure of anhydrous D-mannitol. Powder Diffr. 2003, 18, 214-218.

(89) Su, W.; Hao, H.; Glennon, B.; Barrett, M. Spontaneous Polymorphic Nucleation of D-Mannitol in Aqueous Solution Monitored with Raman Spectroscopy and FBRM. Cryst. Growth Des. 2013, 13, 5179-5187.

(90) Cornel, J.; Kidambi, P.; Mazzotti, M. Precipitation and transformation of the three polymorphs of d-mannitol. Ind. Eng. Chem. Res. 2010, 49, 5854-5862.

(91) Campbell Roberts, S. N.; Williams, A. C.; Grimsey, I. M.; Booth, S. W. Quantitative analysis of mannitol polymorphs. FT-Raman spectroscopy. J. Pharm. Biomed. Anal. 2002, 28, 1135-1147.

(92) Burger, A.; Henck, J. O.; Hetz, S.; Rollinger, J. M.; Weissnicht, A. a.; Stöttner, H. Energy/Temperature Diagram and Compression Behavior of the Polymorphs of D-Mannitol. J. Pharm. Sci. 2000, 89, 457-468.

(93) Ohrem, H. L.; Schornick, E.; Kalivoda, A.; Ognibene, R. Why is mannitol becoming more and more popular as a pharmaceutical excipient in solid dosage forms? Pharm. Dev. Technol. 2014, 19, 257262.

(94) Wagner, C. M.; Pein, M.; Breitkreutz, J. Roll compaction of granulated mannitol grades and the unprocessed crystalline deltapolymorph. Powder Technol. 2015, 270, 470-475.

(95) Tao, J.; Jones, K. J.; Yu, L. Cross-Nucleation between DMannitol Polymorphs in Seeded Crystallization. Cryst. Growth Des. 2007, 7, 2410-2414.

(96) Liu, H.; Vandu, C. O.; Krishna, R. Hydrodynamics of Taylor Flow in Vertical Capillaries: Flow Regimes, Bubble Rise Velocity, Liquid Slug Length, and Pressure Drop. Ind. Eng. Chem. Res. 2005, 44, 4884-4897.

(97) Triplett, K. a.; Ghiaasiaan, S. M.; Abdel-Khalik, S. I.; Sadowski, D. L. Gas-liquid two-phase flow in microchannels Part I: two-phase flow patterns. Int. J. Multiphase Flow 1999, 25, 377-394.

(98) Jayanti, S.; Hewitt, G. F. Hydrodynamics and heat transfer in wavy annular gas-liquid flow: a computational fluid dynamics study. Int. J. Heat Mass Transfer 1997, 40, 2445-2460. 